\title{
Responses of arbuscular mycorrhizal fungi to long-term inorganic and organic nutrient addition in a lowland tropical forest
}

\author{
Merlin Sheldrake ${ }^{1,2} \cdot$ Nicholas P. Rosenstock $^{3} \cdot$ Scott Mangan $^{2,4} \cdot$ Daniel Revillini $^{5} \cdot$ Emma J. Sayer $\mathbb{D}^{2,6}$. \\ Pål Axel Olsson ${ }^{7} \cdot$ Erik Verbruggen $\mathbb{D}^{8} \cdot$ Edmund V. J. Tanner ${ }^{1} \cdot$ Benjamin L. Turner $\mathbb{C}^{2} \cdot$ S. Joseph Wright $\mathbb{B}^{2}$
}

Received: 25 November 2017 / Revised: 13 March 2018 / Accepted: 18 March 2018 / Published online: 13 June 2018

(c) International Society for Microbial Ecology 2018

\begin{abstract}
Improved understanding of the nutritional ecology of arbuscular mycorrhizal (AM) fungi is important in understanding how tropical forests maintain high productivity on low-fertility soils. Relatively little is known about how AM fungi will respond to changes in nutrient inputs in tropical forests, which hampers our ability to assess how forest productivity will be influenced by anthropogenic change. Here we assessed the influence of long-term inorganic and organic nutrient additions and nutrient depletion on AM fungi, using two adjacent experiments in a lowland tropical forest in Panama. We characterised AM fungal communities in soil and roots using 454-pyrosequencing, and quantified AM fungal abundance using microscopy and a lipid biomarker. Phosphorus and nitrogen addition reduced the abundance of AM fungi to a similar extent, but affected community composition in different ways. Nutrient depletion (removal of leaf litter) had a pronounced effect on AM fungal community composition, affecting nearly as many OTUs as phosphorus addition. The addition of nutrients in organic form (leaf litter) had little effect on any AM fungal parameter. Soil AM fungal communities responded more strongly to changes in nutrient availability than communities in roots. This suggests that the 'dual niches' of AM fungi in soil versus roots are structured to different degrees by abiotic environmental filters, and biotic filters imposed by the plant host. Our findings indicate that AM fungal communities are fine-tuned to nutrient regimes, and support future studies aiming to link AM fungal community dynamics with ecosystem function.
\end{abstract}

Electronic supplementary material The online version of this article (https://doi.org/10.1038/s41396-018-0189-7) contains supplementary material, which is available to authorized users.

Merlin Sheldrake

merlinsheldrake@gmail.com

1 Department of Plant Sciences, University of Cambridge, Downing Street, Cambridge CB2 3EA, UK

2 Smithsonian Tropical Research Institute, Apartado 0843-03092 Balboa, Ancón, Republic of Panama

3 Center for Environmental and Climate Research, Lund University, Lund 22362, Sweden

4 Department of Biology, Washington University in St. Louis, St. Louis, MO 63130, USA

5 Department of Biological Sciences, Northern Arizona University, PO BOX 5640, Flagstaff, AZ 86011, USA

6 Lancaster Environment Centre, Lancaster University, Lancaster LA1 4YQ, UK

7 Department of Biology, Lund University, 22362 Lund, Sweden

8 Research Group Plants and Ecosystems (PLECO), Department of Biology, University of Antwerp, Wilrijk, Belgium

\section{Introduction}

Arbuscular mycorrhizal (AM) fungi are an ancient, major group of plant symbionts that facilitate the uptake of limiting soil nutrients by plants in exchange for plant carbon (C) [1]. The majority of tropical trees-which make up 59\% of global forest vegetation-depend on AM fungi [2-5]. Although most lowland tropical soils are strongly weathered and were thought to be P-limited, recent evidence suggests that multiple limiting nutrients interact to limit forest productivity and function [6-9]. To anticipate future effects of anthropogenic change on tropical forest systems, an understanding of how nutrients limit forest productivity is required $[10,11]$. However, AM fungi are severely understudied in tropical forests [12, 13], and despite the wellestablished role for AM fungi in improving plant access to $\mathrm{P}$ [1], their roles in lowland tropical forests remain unclear.

There are two main mechanisms by which changes in nutrient availability could affect AM fungi. Nutrient addition may alleviate direct nutrient limitation of fungal growth, particularly where the background availability of 
nutrients is low. Conversely, nutrient addition could alter the symbiotic exchange of resources between plant and fungal partners, particularly where background nutrient availability is higher [15-16]: AM fungi incur a substantial $\mathrm{C}$ cost to their plant partners [1], and plants are therefore likely to reduce their $\mathrm{C}$ investment in $\mathrm{AM}$ fungi when nutrients are readily available [15]. Furthermore, plants may preferentially allocate $\mathrm{C}$ to AM fungal partners that supply required nutrients under more favourable 'terms of trade' [17-20].

AM fungi are major actors in global $\mathrm{C}$ and nutrient cycles [21, 22], and even small changes in the regulation of C flux into AM fungi could have a large global impact [23]. This is particularly true of tropical forests, which are responsible for at least one third of terrestrial C flux [24]. The availability of nutrients regulates the allocation of plant $\mathrm{C}$ to AM fungi [25], and the addition of nutrients in inorganic or organic form can have quite different effects on nutrient pools in tropical forests and elicit markedly different responses from plants [26]. However, few studies have compared the relative effects of inorganic and organic nutrient additions on AM fungal communities, and to our knowledge, no such studies have taken place outside temperate agricultural settings. This type of comparison is important because experimental inorganic and organic nutrient additions can reveal different aspects of AM fungal ecology. On the one hand, organic matter inputs are the primary route for the cycling of nutrients under natural conditions [27], and simulate the conditions under which the regulatory behaviours governing plant-AM fungal relations have evolved. By contrast, inorganic nutrient additions can highlight the role of specific limiting nutrients, and provide insight into possible ecosystem responses to anthropogenic nutrient deposition.

Two parallel, long-term field experiments in a lowland tropical forest in Panama provided a unique opportunity to unravel the relative importance of the form (organic versus inorganic), amount, and balance of nutrients (the bulk addition of litter versus single or paired inorganic nutrients) on AM fungal ecology. The Gigante Fertilisation Project (GFP) is a factorial NPK addition experiment that allowed us to evaluate AM fungal responses to the addition of inorganic nutrients alone or in factorial combination. The Gigante Litter Manipulation Project (GLMP) at the same site consists of control, litter addition, and litter removal treatments, which allowed us to evaluate AM fungal responses to both a doubling, and the removal of organic matter-a nutrient depletion treatment. Nutrient depletion is an important but rarely performed approach to understand nutrient limitation patterns in ecosystems [28].

Together, these experiments allowed us both to investigate the primary nutrients driving plant-AM fungal interactions and assess the degree to which AM fungal communities are structured by resource-based environmental filters in both components of their 'dual niche': plant roots and soil [29]. Specifically, we hypothesised:

(1) Given the well-established role of AM fungi in plant $\mathrm{P}$ acquisition [1], the low availability of $P$ in weathered lowland tropical soils [30], and the role of P in limiting tree distributions and growth in this region [9, 31], $\mathrm{P}$ addition should cause the strongest changes in AM fungal abundance and community composition.

(2) Nutrient addition should alter the ecological processes structuring AM fungal communities, leading to changes in the degree of relatedness (or phylogenetic dispersion) of AM fungal communities.

(3) Given the different roles played by intra- and extraradical $\mathrm{AM}$ fungal phases in acquiring $\mathrm{C}$ and nutrients respectively, the extra-radical portion of AM fungal communities (those in the soil) should be more sensitive to nutrient additions than the intra-radical portion (those in roots).

(4) The addition of single inorganic nutrients-which can create nutrient imbalances-should have a greater effect on AM fungal metrics than the simultaneous addition or removal of all nutrients with litter manipulation.

\section{Methods}

\section{Site description and experimental design}

We sampled roots and soil in two parallel long-term experiments in a lowland tropical forest in Panama. The GFP was established in 1998, and had been running for 15 years at the time of sampling [8]. The GLMP was started in 2003 , and had been running for nine years at the time of sampling [32].

We sampled from five treatments across the GFP (N, P, $\mathrm{K}$, NP, and unfertilised controls). Each treatment was applied to four replicate $40 \times 40 \mathrm{~m}$ plots across the 38.4-ha study site. Annual doses are $125 \mathrm{~kg} \mathrm{~N} \mathrm{ha}^{-1} \mathrm{yr}^{-1}$ as coated urea, $50 \mathrm{~kg} \mathrm{Pha}^{-1} \mathrm{yr}^{-1}$ as triple superphosphate, and $50 \mathrm{~kg}$ $\mathrm{K} \mathrm{ha}^{-1} \mathrm{yr}^{-1}$ as potassium chloride (SI methods; Figure S1; [8]). Phosphorus addition increased soil phosphate availability by $2800 \%$; K-addition increased $\mathrm{K}$ availability by 91\%; $\mathrm{N}$-addition increased inorganic $\mathrm{N}$ availability by $120 \%$ and reduced $\mathrm{pH}$ from 5.25 to 4.47 [33-35].

The GLMP consists of fifteen $45 \times 45 \mathrm{~m}$ plots. The leaf litter in five litter removal plots is raked up monthly ( $\mathrm{L}-$ ), distributed across five litter addition plots $(\mathrm{L}+)$, with five plots left as controls [30]. Litter addition increased soil phosphate and calcium (Ca) availability by $47 \%$ and $57 \%$, respectively, and did not significantly alter inorganic $\mathrm{N}$. 
Litter removal reduced soil $\mathrm{P}$, inorganic $\mathrm{N}$ and $\mathrm{Ca}$ availability by $35 \%, 43 \%$ and $53 \%$, respectively. Neither litter treatment had significant effects on $\mathrm{K}[36,37]$.

The GLMP litter addition and the GFP inorganic nutrient addition treatments supplied similar amounts of $\mathrm{N}$ and $\mathrm{K}$ to the plots as the inorganic $\mathrm{N}$ - and $\mathrm{K}$-addition treatments (143 vs. $125 \mathrm{~kg} \mathrm{Nha}^{-1} \mathrm{y}^{-1}$ and 39 vs. $50 \mathrm{~kg} \mathrm{Kha}^{-1} \mathrm{y}^{-1}$ for the GLMP and GFP, respectively). In contrast, the litter addition treatment added only $12 \%$ of the $\mathrm{P}$ added in the GFP (5.8 $\mathrm{kg} \mathrm{ha}^{-1} \mathrm{y}^{-1}$ vs. $50 \mathrm{~kg} \mathrm{ha}^{-1} \mathrm{y}^{-1}$; [26]), because greater inputs of inorganic $\mathrm{P}$ were necessary to overcome the $\mathrm{P}$ sorption common to the soils at the study site.

\section{Sampling}

We sampled soil and roots from the four replicate N, P, K, $\mathrm{NP}$ and control plots in the GFP and from the five replicate $\mathrm{L}-, \mathrm{L}+$ and control plots in the GLMP (total of 35 plots) over 2 weeks in September 2012, at the peak of the growing season. In each plot, we collected 81 soil samples $(9 \times 9$ grid) at $0-10 \mathrm{~cm}$ depth, and composited them to make one sample per plot. To control for the effects of host identity on AM fungal parameters, we sampled roots from seedlings of seven of the most common tree species at the study site, collecting 4-6 seedlings per species per plot (c. 1300 seedlings in total; SI methods). In using seedlings, this study differs from previous studies at this site that used mixed root samples from cores $[36,38]$. In this study, we do not provide an analysis of individual seedling species.

\section{AM fungal abundance}

We quantified colonisation of seedling roots by AM fungi using microscopy (staining with trypan blue), as described in [39]; used the neutral lipid fatty acid (NLFA) $16: 105$ as a biomarker for extra-radical AM fungal biomass in the soil ([40]; SI methods); and extracted and counted spores from the soil. We identified spores to family level using morphological characteristics, with reference to the International Culture Collection of Arbuscular and VesicularArbuscular Mycorrhizal Fungi (INVAM; https://invam. wvu.edu; SI methods). The use of the biomarker lipid provides a root length-independent measure of net AM fungal abundance. Sheldrake et al. [39] previously published the colonisation and NLFA data from the GFP (N, P, $\mathrm{NP}$, and $\mathrm{C}$ treatments).

\section{DNA extraction and sequencing}

Root and soil samples were individually pulverised in a homogeniser prior to DNA extraction (TissueLyser II, Qiagen). An equal mass of each root sample was pooled to make one composite sample per species per plot. We extracted DNA from pulverised roots and soil using MoBio PowerPlant and PowerSoil DNA isolation kits according to the manufacturer's instructions (MoBio Laboratories Inc., Carlsbad, CA, USA). We amplified the partial small subunit (SSU) region of $18 \mathrm{~S}$ ribosomal DNA $(c .550 \mathrm{bp})$ with the universal eukaryotic primer NS41 [41] and the AM fungalspecific primer AM1, which amplifies the major families of the Glomeromycota [42]. Amplicon libraries were sequenced on an FLX Titanium system (Roche, Basel, Switzerland) at the Cambridge DNA Sequencing Facility (Department of Biochemistry, University of Cambridge, UK).

\section{Bioinformatic analysis}

Bioinformatic processing followed [36]. Briefly, reads were removed from the data set if they had $>1$ error in the MID barcode sequence, $>2$ errors in the forward primer, were shorter than $200 \mathrm{bp}$, or had an average quality score below 25 over any $40 \mathrm{bp}$ portion of the sequence. Clustering was performed using the algorithm Clustering 16S rRNA for Operational Taxonomic Unit (OTU) Prediction (CROP; [43]). Sequence alignment was performed with the software MAFFT v7.149b [44] and improved with MUSCLE [45]. We used the Basic Local Alignment Search Tool (BLAST; [46]; minimum e-value $10^{-30}$ ) on one representative sequence from each cluster iteratively against three databases in the following order of preference: (i) sequences from Krüger et al. [47]; (ii) all virtual taxa (VT) from the MaarjAM AM fungal sequence database (www.maarjam. botany.ut.ee); and (iii) all $18 \mathrm{~S}$ glomeromycotan sequences from the SILVA database. Clusters were named based on matches to database entries at $>97 \%$ similarity covering a minimum of $80 \%$ of the query sequence. Where clusters did not match a VT at $>97 \%$, we assigned a name based on the highest VT match and phylogeny (e.g., Glomus_OTU1). Raw sequence data were deposited in the International Nucleotide Sequence Database Sequence Read Archive (accession no. SRP076949). Parts of the sequencing data from soil and seedlings in N, P, NP and control plots was published in support of a previous article [39].

\section{Statistical analysis}

All statistical analyses were conducted in $\mathrm{R}$, version 3.1.2 (R Development Core Team, 2014).

We performed separate analyses for GFP and GLMP due to their different designs. The GFP includes four replicates per treatment in an incomplete block design, and 'replicate' was used in all models as a spatial blocking term to control for natural variation across the site [8]. For GFP data, we tested for $\mathrm{N} \times \mathrm{P}$ interactions (omitting the $\mathrm{K}$ treatment) using factorial models, and for the $\mathrm{K}$ treatment in a separate 
one-way model with a single 'treatment' term, using treatment contrasts to test the significance of $\mathrm{K}$-addition relative to controls (we did not sample from all treatments so could not use the full factorial design). For the analysis of GLMP data, we built one-way models with a single 'litter treatment' term, using treatment contrasts to compare each treatment with controls. Each experiment had its own set of control plots. We calculated log response ratios and confidence intervals to allow visual comparison between experiments [48]. The SI presents figures showing the absolute values of variables.

To determine overall root AM fungal responses to treatments, we averaged across seedling species to calculate a pooled root response for each metric and plot. Three of the seedling species were absent from the litter removal treatment. To make results comparable between all treatments, we present only analyses based on the four remaining species. Unless otherwise indicated, analysis of all seven species led to the same conclusions.

\section{Analysis of AM fungal communities}

To account for variation in the number of sequences among samples, we used a variance stabilising (VS) transformation of the OTU table, implemented with the DESeq2 package [49]. VS transformations use a mixture model framework based on the negative binomial distribution, and avoid the need for rarefaction, which fails to account for overdispersion and can bias the results towards false positives [50, 51]. We performed all subsequent analysis on the VS transformed OTU table, with root values calculated as the plot means of individual seedling species, and using the copy number of DNA sequences as a measure of relative abundance of OTUs (SI methods).

To examine the effect of experimental treatments on AM fungal community composition, we used multivariate generalised linear models (M-GLMs) with negative binomial error structures using the mvabund package [52], building separate models for root and soil communities. To compare the relative effects of treatment on root and soil communities, we built an M-GLM to test for the interaction between experimental treatment and 'sample type' (root or soil). We evaluated the degree to which individual OTUs were affected by litter manipulation using DESeq2 [49], which estimates the effect size of treatments relative to controls (as logarithmic fold change; SI methods).

We asked whether experimental treatments altered the degree of relatedness among taxa in AM fungal communities (or phylogenetic dispersion), using the Net Relatedness Index (NRI) as an index of community phylogenetic structure. Positive values of NRI indicate that taxa in a community are on average more closely related to each other than to members of the regional taxon pool (phylogenetically clustered), and negative values indicate that taxa in a community are less closely related (phylogenetically over-dispersed; [53]; SI methods).

\section{Univariate analysis of AM fungal abundance and diversity}

We used linear models to analyse: (i) the concentration of NLFA 16:105 in the soil and, (ii) the percentage of seedling root length colonised by AM fungi. We analysed spore counts using generalised linear models (GLMs) with Poisson errors $[54,55]$. We built separate models for the total spore number and the number of spores in each family. Spatial blocking terms were included for the above analyses. We analysed the total number of AM fungal OTUs (richness), the proportional abundance of the most dominant taxon (predominance), and the NRI metric with linear mixed-effects models (lme4 package; [56]). The significance of fixed effects was assessed using likelihood ratio tests (LRT) and parametric bootstrapping. We modelled the relationship between occurrence frequency (the proportion of plots in which a given OTU is found) of AM fungal taxa in soil and occurrence frequency in root communities, using fixed dispersion beta regression (SI methods).

Additional details of all procedures and analyses are given in the SI methods.

\section{Results}

\section{AM fungal abundance}

The amount of the AM fungal biomarker (NLFA 16:105) in the top $10 \mathrm{~cm}$ of mineral soil was $c .30 \%$ lower with $\mathrm{N}$ addition and $c .25 \%$ lower with $\mathrm{P}$-addition $\left(F_{1,9}=11.2, P\right.$ $=0.009 ; F_{1,15}=6.3, P=0.03$, respectively; Fig. $\left.1 \mathrm{~b}, \mathrm{~S} 2\right)$. There was a significant overall effect of litter manipulation on the amount of NLFA 16:165 in the soil, suggesting a trend towards a positive effect of litter addition and a negative effect of litter removal $\left(F_{2,8}=5.4, P=0.03\right.$, Fig. 1b, Figure S2), but individual treatment contrasts were not statistically significant.

Neither inorganic nutrient addition nor litter manipulation influenced the total number of AM fungal spores in the soil (Fig. 2, S3). Across all treatments, we identified spores belonging to three families, Glomeraceae, Acaulosporaceae and Gigasporaceae. The Glomeraceae constituted c. $90 \%$ of the total spore pool, Acaulosporacea $c$. $10 \%$, and Gigasporaceae $c .0 .4 \%$. Separate analyses by family showed that Acaulosporaceae spores were more abundant in plots where $\mathrm{N}$ and $\mathrm{P}$ were added together $(\mathrm{N}+\mathrm{P})$ relative to the treatments where either nutrient was added alone $(\mathrm{N} \times \mathrm{P}$ interaction, $\chi^{2}=6.1, P=0.01$; Fig. 2, S3). There was no effect of inorganic nutrient addition on spores of the Glomeraceae 
(a) \% root length colonised

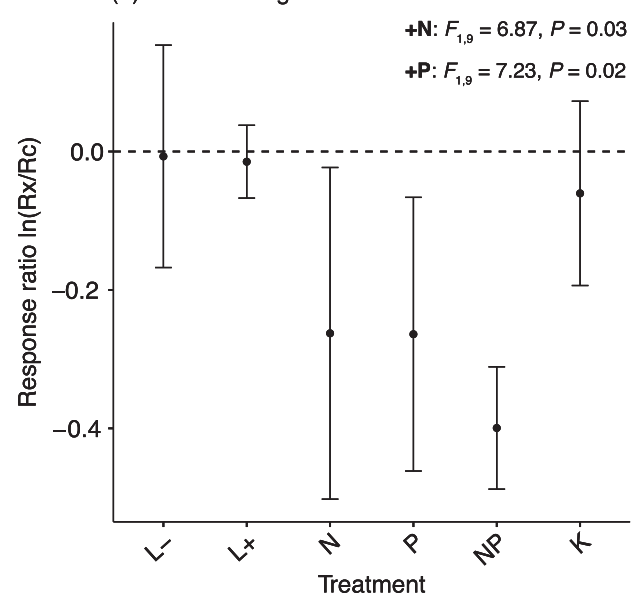

(b) NLFA 16:1 105

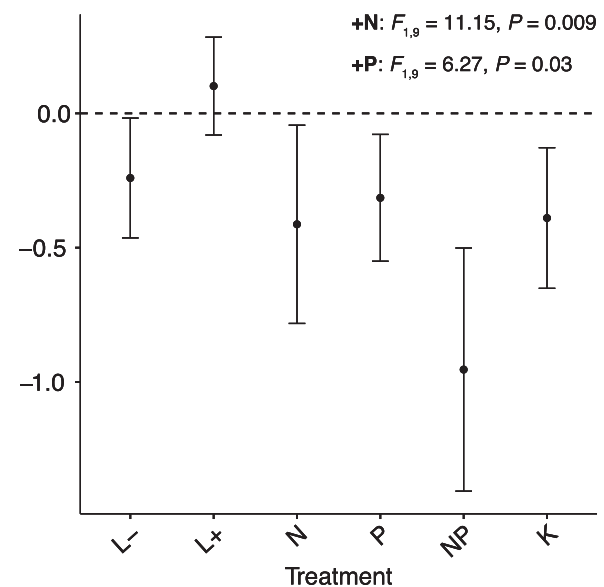

significant (ANOVA: $F_{2,8}=5.4, P=0.03$ ), although neither treatment significantly differed from controls. Values are log response ratios (not the predictions of the statistical models), and error bars represent $95 \%$ confidence intervals obtained by bootstrapping with 9999 replicates. L

- litter removal, $\mathrm{L}+$ litter addition, $\mathrm{N}$ nitrogen, $\mathrm{P}$ phosphorus, $\mathrm{NP}$ nitrogen + phosphorus, $\mathrm{K}$ potassium
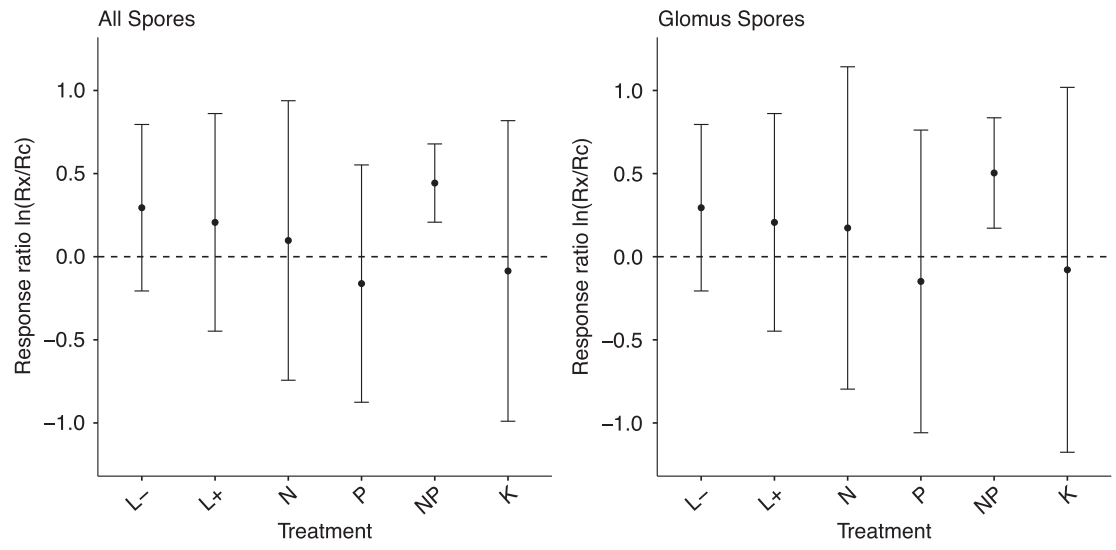

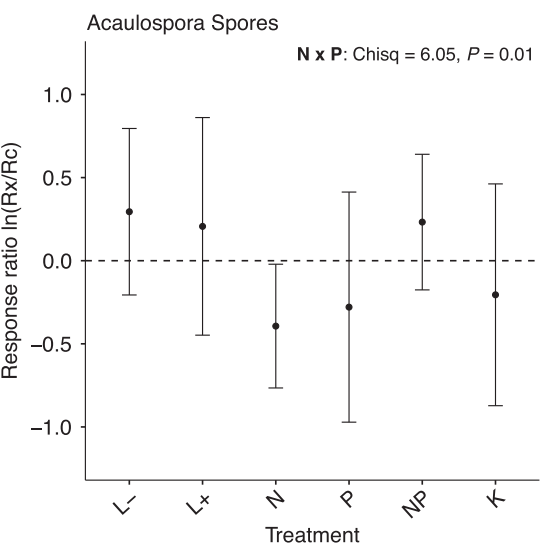

Fig. 2 Effect of long-term inorganic and organic nutrient addition on the abundance of AM fungal spores in the top $10 \mathrm{~cm}$ of forest soil. Significance was assessed using separate generlised linear models for GLMP and GFP; significant effects are inset in panels above. Values are log response ratios (not the predictions of the statistical models), and error bars represent $95 \%$ confidence intervals obtained by bootstrapping with 9999 replicates. L- litter removal, L+ litter addition, N nitrogen, $\mathrm{P}$ phosphorus, NP nitrogen + phosphorus, $\mathrm{K}$ potassium or Gigasporaceae and no effect of litter manipulation on the number of spores from any family.

AM fungal colonisation of seedling roots was c. $18 \%$ lower with both $\mathrm{N}$ - and P-addition $\left(F_{1,9}=6.9, P=0.03\right.$; $F_{1,9}=7.2, P=0.02$, respectively; Fig. 1a, S4) but was unaffected by litter manipulation. When the analysis was repeated with the additional three species (seven in total), there was a marginally significant $\mathrm{N} \times \mathrm{P}$ interaction, whereby AM fungal colonisation of seedling roots was lower with the addition of $\mathrm{N}$ and $\mathrm{P}$ together compared to either $\mathrm{N}$ or $\mathrm{P}$ addition alone $\left(\mathrm{N} \times \mathrm{P}\right.$ interaction: $F_{1,9}=5.0$, $P=0.05)$.
K-addition had no significant effects on any of the metrics assessed in this study and is therefore not reported.

\section{AM fungal richness and predominance}

Rarefaction curves for each sample indicated that sequencing intensity was sufficiently high to detect the majority of OTUs and that sampling effort was sufficient to capture AM fungal diversity across the sites (Figure S7). A total of 222,748 sequences were retained after quality control and clustered into 226 OTUs, of which 62 OTUs (corresponding to 22,069 sequence reads, $9.9 \%$ of total reads) matched 
either non-glomeromycotan taxa in the sequence databases or failed to match with any accessions in the database. OTUs remaining after blasting, filtering, merging and trimming (exclusion of OTUs arising from only one sample or with a total of five reads or fewer), represented a total of 200,554 sequences. The number of OTUs and sequences per sample averaged 24 OTUs (range: 9-45) and 1146 sequences (range: 328-2117).

The total number of AM fungal OTUs (OTU richness) was c. $35 \%$ higher in soil than in roots in both the GFP and GLMP $(\mathrm{LRT}=42.4, P<0.001$ and LRT $=35.6, P<$ 0.001 for GFP and GLMP, respectively). The mean number of OTUs was similar between experiments both for soil (GFP: 34 OTUs and GLMP: 35 OTUs) and root samples (GFP: 21 OTUs and GLMP 23). The occurrence frequency of AM fungal OTUs in soil and roots was strongly correlated (beta regression; $\chi^{2}=196.3, \quad P<$ 0.001; Figure S5), indicating that AM fungal OTUs that were common in soil communities also tended to be common in root communities. However, the proportional abundance of the most dominant taxon at a site (predominance) was higher in root AM communities than soil communities (LRT $=42.0, P<0.001$; Figure S6). The SI discussion provides a full description of sequencing results.

$\mathrm{N}$-addition reduced OTU richness in both soil and roots $(\mathrm{LRT}=17.9, P<0.001$, Fig. 3a, b, S7), but the negative effect of $\mathrm{N}$-addition on OTU richness was stronger in soil than in root samples $(\mathrm{N} \times$ 'sample type' interaction; LRT $=6.9, P=0.03$; Fig. 3a, b, S8). Predominance in both sample types was $c .27 \%$ higher with $\mathrm{N}$-addition (LRT = 17.9, $P<0.001$; Fig. 3c, d, S7). P-addition did not affect OTU richness or dominance; however, $\mathrm{P}$ - and $\mathrm{N}$-addition together mitigated reductions caused by $\mathrm{N}$-addition $(\mathrm{N} \times \mathrm{P}$ interaction: $\mathrm{LRT}=8.1, P=0.007$; Fig. $3 \mathrm{a}, \mathrm{b})$. In the GLMP, there was a non-significant trend towards lower OTU richness in the soil in both litter manipulation treatments relative to controls ('treatment' term: LRT $=$ 4.4, $P=0.17$; Fig. 3a, b, S8). Predominance increased with litter addition in both soil and root communities (Full model LRT $=9.4, P=0.02$; Fig. 3c, d) but was unaffected by litter removal.

\section{AM fungal community composition}

Within all treatments, soil and root samples had distinct AM fungal community composition (treatment $\times$ sample type interaction: Deviance $=960.3, P=0.001$; Figure S9) and a greater number of OTUs were affected by nutrient manipulation in the soil than in roots (Fig. 4 and Table S1). There was a clear separation of AM fungal communities in plots with P-addition, regardless of sample type (soil: Deviance $=608.3, P<0.001$; roots: Deviance $=268.7, P=0.002$;
Fig. 5a, b). In soil samples, the effect of P-addition on AM fungal community composition differed according to whether $\mathrm{N}$ was also added $(\mathrm{N} \times \mathrm{P}$ interaction; Deviance $=254.8$, $P=0.001$; Figs. 5a, 4). A similar pattern was observed in root communities, although the $\mathrm{N} \times \mathrm{P}$ interaction was only marginally significant $\quad$ (Deviance $=189.3, \quad P=0.06$; Figs. 5b, 4) and there was no effect of $\mathrm{N}$-addition alone. Litter removal altered AM fungal community composition in both soil and roots (soil: Deviance $=202.3, P<0.001$; roots: Deviance $=181.3, P=0.007$; Fig. 5a, b), whereas litter addition only altered the composition of communities in soil (Deviance $=131.5, P=0.01$; Fig. 5a, b). Tables S2 and S3 present all OTUs significantly affected by experimental treatments.

AM fungal communities were no more phylogenetically clustered or dispersed than expected by chance (i.e., relative to simulated null communities), and there was no effect of any experimental treatment on the relatedness of taxa in AM fungal communities when the analysis was conducted with four seedling species. However, when the analysis was repeated with the additional three seedling species, $\mathrm{N}+\mathrm{P}$ reduced the relatedness of taxa in AM fungal communities relative to treatments where they were added separately, across root and soil communities $(\mathrm{N} \times \mathrm{P}$ interaction: $\mathrm{LRT}=$ 7.0, $P=0.01$; Figure S11).

\section{Discussion}

\section{Primary nutrients driving plant-AM fungal relations}

We found support for our hypothesis that the addition of inorganic nutrients should have a stronger effect than litter addition. Both $\mathrm{N}$ - and $\mathrm{P}$-addition reduced AM fungal abundance in roots and soil (colonisation and NLFA 16:1 $\omega 5$, respectively) in a similar manner (Fig. 1), whereas litter addition had no effect. Nutrient addition may affect AM fungi directly by alleviating fungal nutrient limitation (leading to an increase in fungal abundance), or indirectly, by altering plant $\mathrm{C}$ investment in their AM fungal symbionts. The second alternative may involve selection for AM fungi that provide more nutritional benefits or are better competitors for plant $\mathrm{C}$, usually leading to a decrease in fungal abundance [57]. Hence, the observed reductions in AM fungal abundance imply that plants reduced their investment in AM fungi as nutrients became more readily available following $\mathrm{N}$ - and $\mathrm{P}$-addition, and suggest a role for $\mathrm{AM}$ fungi in both plant $\mathrm{N}$ and $\mathrm{P}$ acquisition under normal conditions [24]. That no nutrient treatment increased AM fungal abundance suggests that AM fungi at this site are not directly limited by nutrients apart from root-derived $\mathrm{C}$ [15]. These findings are consistent with the results of a global meta-analysis of AM fungal responses to $\mathrm{N}$ and $\mathrm{P}$, 
(a) OTU richness (root)

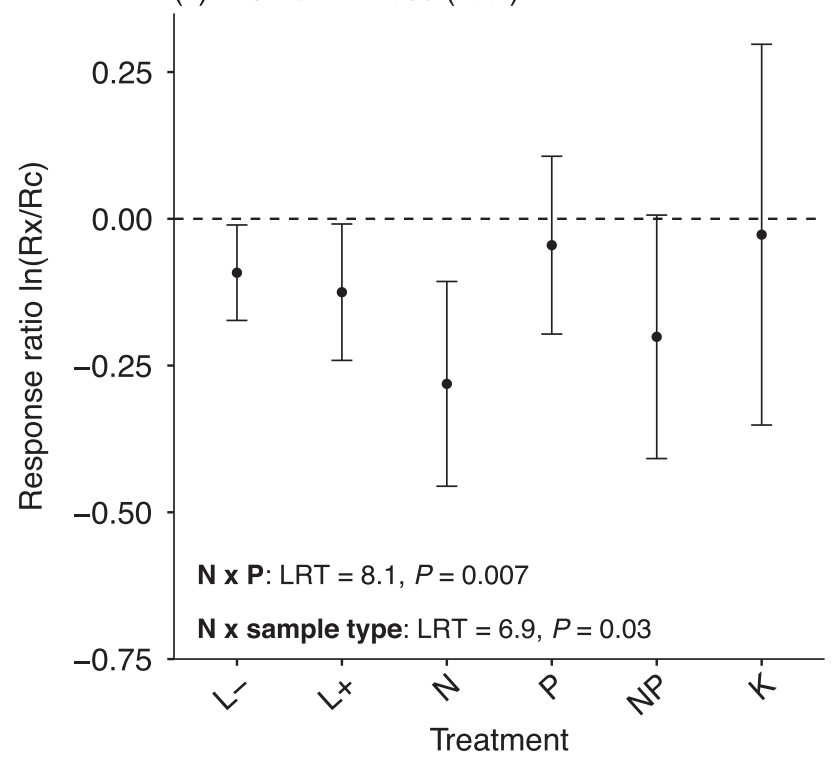

(c) OTU predominance (root)

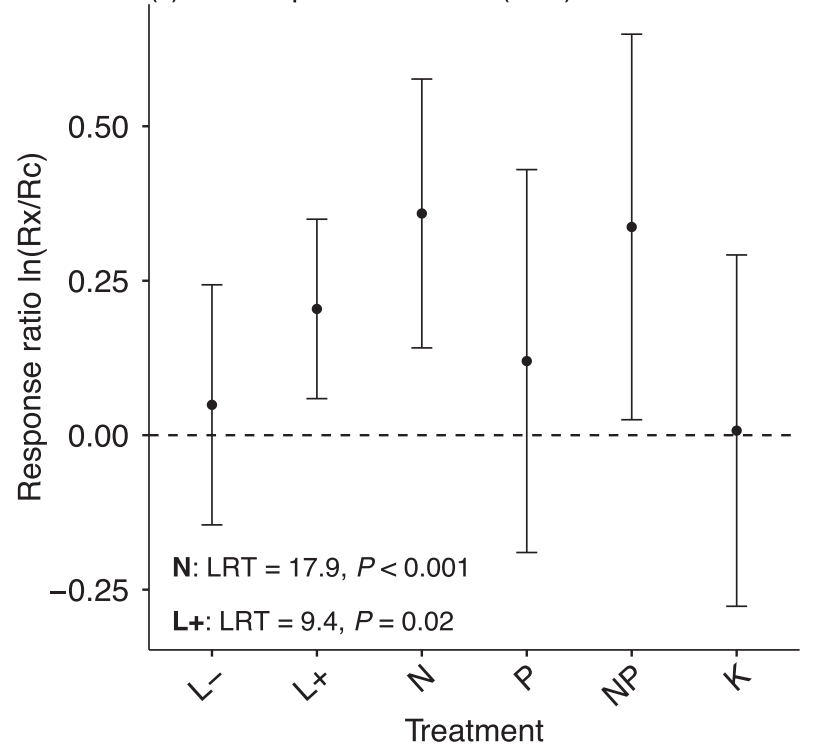

Fig. 3 Effect of long-term inorganic and organic nutrient on the AM fungal OTU richness (a, b) and predominance (proportional abundance of the dominant AM fungal OTU; c, d) in soil and root samples. Significance was assessed using separate linear models for GLMP and GFP; significant effects are inset in panels above (LRT likelihood ratio

which found that overall, $\mathrm{N}$ and $\mathrm{P}$ decreased $\mathrm{AM}$ fungal abundance, despite significant variability in AM fungal responses to $\mathrm{N}$ [58].

Previous studies at this site have found strong evidence for plant $\mathrm{K}$ limitation, notably in root responses [8, 33, 35]. We observed no significant effects of K-addition on any AM fungal metric. This suggests that AM fungi do not play a role in plant $\mathrm{K}$ nutrition in this system, and/or that root $\mathrm{C}$ allocation to AM fungi does not vary as a function of plant $\mathrm{K}$ status. (b) OTU richness (soil)

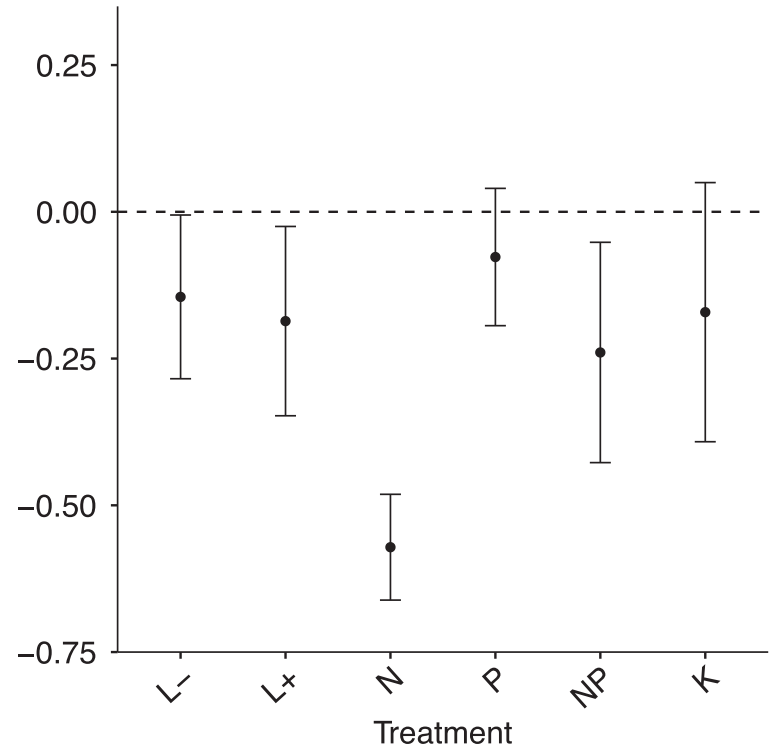

(d) OTU predominance (soil)

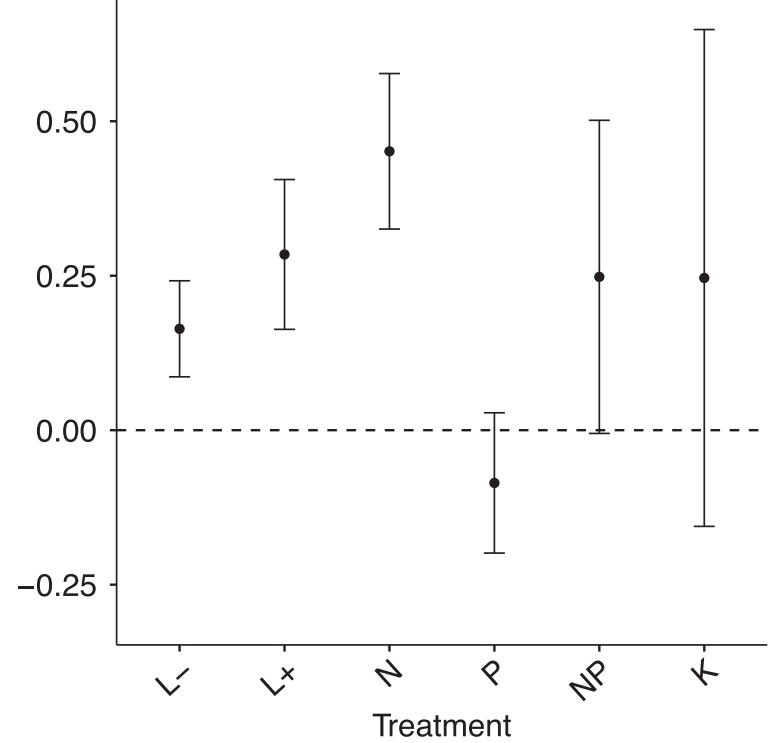

test). Values are log response ratios (not the predictions of the statistical models), and error bars represent $95 \%$ confidence intervals obtained by bootstrapping with 9999 replicates. L- litter removal, L+ litter addition, $\mathrm{N}$ nitrogen, $\mathrm{P}$ phosphorus, NP nitrogen + phosphorus, $\mathrm{K}$ potassium

Although, N- and P-addition reduced AM fungal abundance by similar amounts (Fig. 1), AM fungal community parameters responded quite differently to $\mathrm{N}$ - versus $\mathrm{P}$ addition. $\mathrm{N}$-addition reduced OTU richness and increased predominance (Fig. 3), whereas P-addition alone had no effect on OTU richness but when added with $\mathrm{N}$ (the $\mathrm{N}+\mathrm{P}$ treatment), alleviated the reduction in OTU richness associated with $\mathrm{N}$-addition (Fig. 3). Furthermore, $\mathrm{P}$-addition had much stronger effects on overall community composition than $\mathrm{N}$-addition (Fig. 5). The reduction in richness and 
Fig. 4 Number of AM fungal OTUs significantly affected by long-term inorganic and organic nutrient addition. Significance was ascertained based on negative binomial Wald tests using standard maximum likelihood estimates for generalised linear models with $P$-values $(\alpha=0.05)$ adjusted for multiple comparisons, as implemented in the DESeq2 package. $\mathrm{L}-$ litter removal, $\mathrm{L}+$ litter addition, $\mathrm{N}$ nitrogen, $\mathrm{P}$ phosphorus, NP nitrogen + phosphorus, K potassium. Colours correspond to AM fungal genera

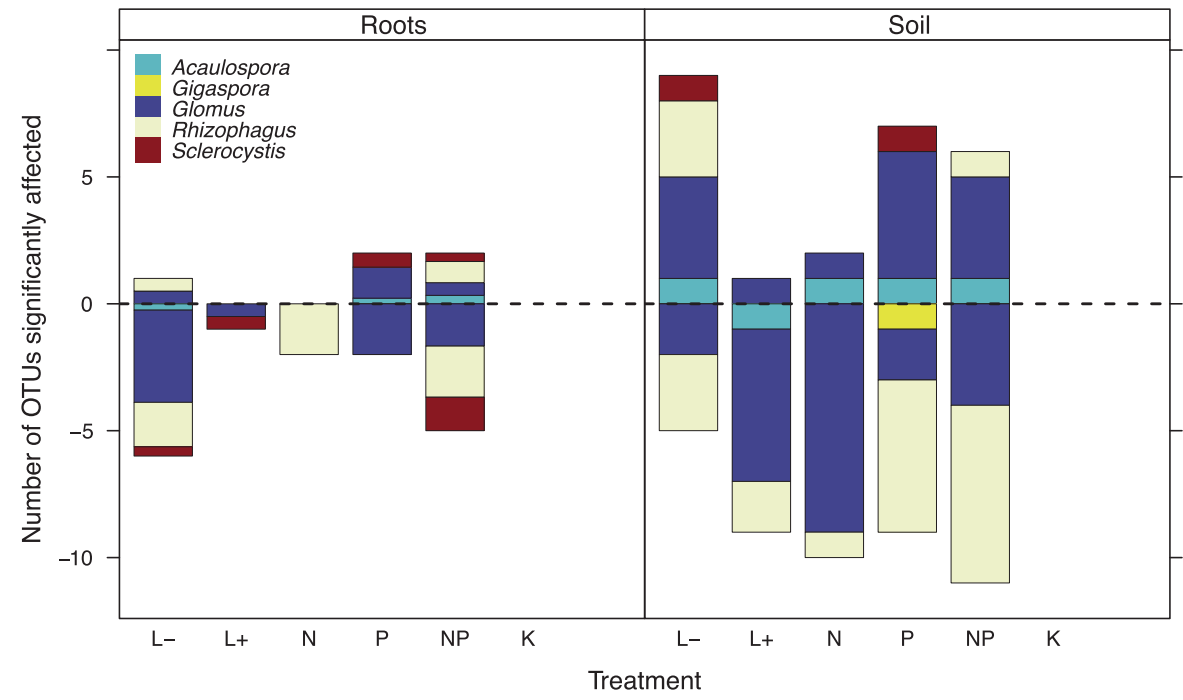

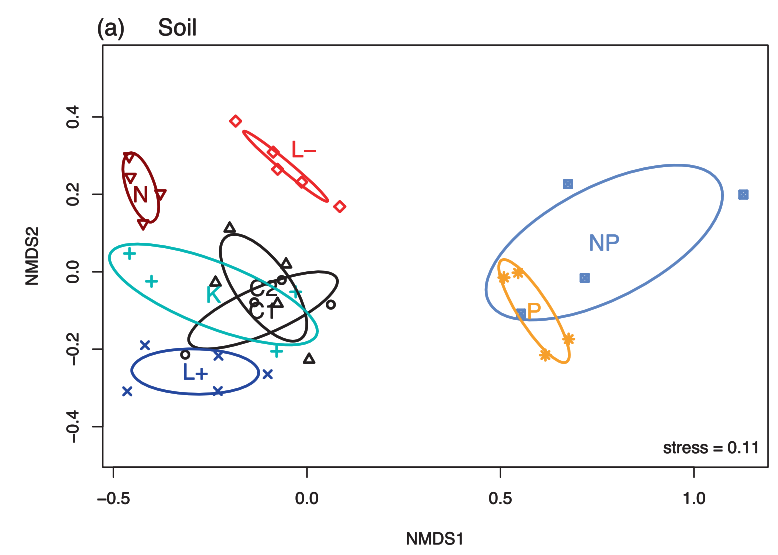

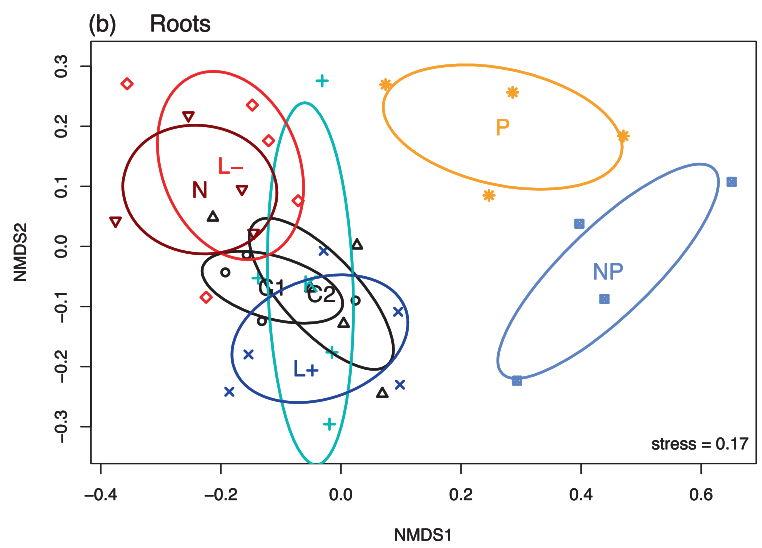

Fig. 5 Non-metric multidimensional scaling (NMDS) ordination plot showing changes in AM fungal community composition in response to inorganic and organic nutrient addition in soil (a) and root (b) samples in a lowland tropical forest in Panama. 'Site' scores are shown and ellipses describe 95\% confidence limits. Ordinations are based on Bray-Curtis dissimilarity. Axes are scaled to half-change (HC) units, by which one $\mathrm{HC}$ unit describes a halving of community similarity. $\mathrm{C} 1$ control treatment in GFP, C2 control treatment in GLMP, L- litter removal, $\mathrm{L}+$ litter addition, $\mathrm{N}$ nitrogen, $\mathrm{P}$ phosphorus, $\mathrm{NP}$ nitrogen + phosphorus, $\mathrm{K}$ potassium. Colours and symbol shapes correspond to different treatments increase in predominance following $\mathrm{N}$-addition suggests that plants increasingly rely on a subset of AM fungi when $\mathrm{P}$ becomes more limiting. By contrast, when P limitation was reduced, AM fungi in soil and roots maintained their diversity despite the decline in abundance, perhaps pointing to a role for the fungal partners in providing other nutrients or benefits to plants. These findings suggest that $\mathrm{N}$ - and Padditions affect plant-AM fungal relations in different ways and agree with a previous study at this site which suggested a strong effect of P-addition on plant-AM fungal relations without a concomitant effect of $\mathrm{N}$-addition [36].

We found that addition of $\mathrm{N}$ and $\mathrm{P}$ in combination reduced the relatedness of taxa in AM fungal communities relative to treatments where $\mathrm{N}$ and $\mathrm{P}$ were added separately. Taxa that share a common evolutionary history can also share traits and ecological functions [59, 60]. According to this principle - known as phylogenetic trait conservatism an increase in phylogenetic dispersion suggests that $\mathrm{AM}$ fungal communities in $\mathrm{N}+\mathrm{P}$ treatments experience increased competitive interactions among taxa, preventing closely related and functionally similar taxa (those sharing a common niche) from co-occurring. This possibility is consistent with a reduction in $\mathrm{C}$ supplied by plant hosts in response to $\mathrm{N}$ and $\mathrm{P}$ addition (as suggested by reduced $\mathrm{AM}$ fungal abundance), which would force AM fungi to compete for increasingly limited resources. However, the effect of $\mathrm{N}+\mathrm{P}$ treatments on phylogenetic structure was weak and should be interpreted with caution.

Our results contrast with an earlier study at this site which found that AM fungal colonisation in mixed root cores decreased with $\mathrm{N}$-addition but increased with $\mathrm{P}$ addition [35]. Wurzburger and Wright [35] used mixed cores, dominated by the roots of sun-exposed canopy adults, while we sampled roots from deeply shaded, understory seedlings. Given that photosynthetically fixed $\mathrm{C}$ represents 
the plant currency of symbiotic exchange, different degrees of light limitation could cause adult and seedling plants to adjust their investment in AM fungi in different ways in response to nutrient addition. However, in the present study, AM fungal abundance in the soil (as indicated by the lipid biomarker) shows a similar response to nutrient addition as the AM fungal colonisation of seedling roots, suggesting that seedling colonisation levels reflect response of extraradical AM fungal abundance to nutrient addition. We lack a good explanation for this discrepancy with our findings.

Interpretation of the effects of $\mathrm{N}$-addition on AM fungal communities is complicated because ten years of $\mathrm{N}$-addition reduced the $\mathrm{pH}$ from 5.25 to 4.47 [32]. However, the variety of $\mathrm{AM}$ fungal responses to reduced $\mathrm{pH}$ in the literature makes it difficult to determine which responses can be attributed to the decrease in $\mathrm{pH}$. Low $\mathrm{pH}$ has been shown to reduce AMF spore production, colonisation and extraradical hyphal growth [61-64], and reduce AMF OTU richness [65]. Accordingly, many of the effects of $\mathrm{N}$ that we observed in this study may be explained by a reduction in $\mathrm{pH}$. Nonetheless, it is unlikely that $\mathrm{pH}$ entirely explains the observed effects of $\mathrm{N}$ on AM fungal community composition because: (i) the $\mathrm{N}+\mathrm{P}$ treatments clustered far more closely with $\mathrm{P}$ treatments than with $\mathrm{N}$ treatments (Fig. 5), and (ii) The addition of $\mathrm{N}+\mathrm{P}$ did not reduce OTU richness, while the addition of $\mathrm{N}$ alone did. If lower soil $\mathrm{pH}$ explained the observed $\mathrm{N}$ effect, we would expect the AM fungal community in the $\mathrm{N}+\mathrm{P}$ treatments (soil $\mathrm{pH} c$. 4.8) to have a similar community composition and richness to $\mathrm{N}$ treatments (soil $\mathrm{pH}$ c. 4.5).

\section{AM fungal responses in both components of their 'dual niche'}

Soil and root communities differed from each other across all treatments (Figure S9). This may be because different AM fungal taxa have contrasting life history [66] or rootcolonisation strategies $[67,68]$, which can alter the relative proportion of AM fungal taxa in intra- versus extra-radical phases $[69,70]$.

We hypothesised that AM fungal communities would be more sensitive to nutrient manipulation in soil than in roots because the intra- and extra-radical AM fungal phases play different roles in nutrient acquisition (the extra-radical phase obtaining nutrients from the substrate, and intraradical phase obtaining fixed $\mathrm{C}$ from the plant). Our results support this, as most treatments ( $\mathrm{N}$-addition, $\mathrm{P}$-addition, $\mathrm{L}+$ and $\mathrm{L}-$ ) altered $\mathrm{AM}$ fungal communities more strongly in the soil than roots (Fig. 5). Similar effects of P-addition on AM fungi were reported in a recent study in maize fields [71], and there is evidence that intra- and extra-radical phases are subject to different degrees of limitation depending on the relative availability of $\mathrm{N}, \mathrm{P}$ and plant $\mathrm{C}$
[72]. In this study, the greater sensitivity to experimental treatments of AM fungi in the soil suggests that extraradical phases may be more sensitive to abiotic environmental filters, and intra-radical phases more sensitive to filters imposed by the plant host (such as preferential allocation; [73]). This intriguing possibility warrants further investigation.

Together with other studies performed at this site, our findings indicate that some treatments caused changes in overall plant belowground allocation (measured as fine root biomass) without appearing to affect plant allocation to AM fungi, and vice versa, suggesting a fine degree of control over $\mathrm{C}$ allocation to different belowground structures. $\mathrm{K}$ addition reduced fine root biomass $[8,33,35]$ while litter addition increased fine root biomass [74], with neither treatment affecting AM fungal abundance or communities (this study). By contrast, $\mathrm{N}$ - and P-addition reduced plant belowground allocation to fine roots [35], while also reducing AM fungal abundance and altering AM fungal communities and increasing the sporulation of Acaulosporaceae when added together (this study).

\section{Inorganic versus organic nutrient addition}

As expected, the effects of litter manipulation on AM fungal abundance and community composition were generally not as strong as the effects of inorganic nutrient addition. This may be because inorganic treatments-particularly $\mathrm{P}$ added a greater amount of fast-release nutrients than the litter addition treatment. As the amount of $\mathrm{P}$ added in the inorganic P-addition treatment was much greater than the amount added with litter, the potential influence of nutrient source is confounded by differences in nutrient amount. However, findings from other studies conducted at this site suggest that $\mathrm{N}$ and $\mathrm{P}$ added as litter were more available (in the case of $\mathrm{N}$ ) or comparably available (in the case of $\mathrm{P}$ ) to plants as the inorganic $\mathrm{N}$ and $\mathrm{P}$ added in the GFP. For example, in a comparative analysis published in 2012, litter $\mathrm{N}$ concentrations increased with litter addition but not with inorganic $\mathrm{N}$-addition, despite the fact that both treatments supplied similar amounts of $\mathrm{N}$, indicating that $\mathrm{N}$ was more available to plants in the GLMP than in the GFP (a more recent analysis of the GFP only found an increase in litter N on the $\mathrm{N}$-addition plots) [75]. By contrast, although the litter addition treatment supplied only c. $12 \%$ of the $\mathrm{P}$ added as inorganic fertiliser, the estimated additional P-return with increased litterfall was comparable between litter addition and inorganic $\mathrm{P}$ treatments indicating that the available proportion of $\mathrm{P}$ added in the GLMP was greater than that added in the GFP (c. $1.2 \mathrm{~kg} \mathrm{Pha}^{-1} \mathrm{y}^{-1}$ versus $1.4 \mathrm{~kg} \mathrm{Pha}^{-1}$ $\left.\mathrm{y}^{-1} ;[25]\right)$. Consequently, if the effects of inorganic N- and P-addition were solely due to plants altering their $\mathrm{C}$ investment in AM fungi in response to requirements 
(according to the trade balance model; [24]), we would expect to see comparably large effects of litter addition on AM fungal abundance and AM fungal communities in roots.

However, despite the large amounts of nutrients added with litter, AM fungal abundance in roots was unchanged (Fig. 1a), and AM fungal abundance in soil tended to increase in response to litter addition. These findings suggest that plants may have experienced the increases in $\mathrm{N}$ or $\mathrm{P}$ from organic versus inorganic sources in different ways.

We propose three possible reasons for the distinct responses of AM fungi to nutrients from organic versus inorganic sources. First, AM fungi are better than plant roots at acquiring nutrients from organic nutrient pools as opposed to inorganic pools, such that plant $\mathrm{C}$ allocation to their AM fungal associates were maintained despite the net increases in the amount of nutrients on the forest floor following litter addition. In other words, plants still needed AM fungi to fulfil the same nutritional function even though the supply of nutrients from organic matter had increased [34]. This possibility is also raised by Vargas et al. [76], who reported increased AM fungal root colonisation in response to substantial organic matter inputs after a hurricane. A second possibility is that nutrient stoichiometry (as opposed to the absolute quantity of a nutrient) regulates plant-AM fungal relations [24, 77, 78], and the addition of one or two inorganic nutrients, such as in the $\mathrm{N}-, \mathrm{P}-$, and $\mathrm{N}$ + P-addition plots, may have a larger effect on AM fungi than litter addition by creating greater nutrient imbalances (and thus potentially greater plant limitation and demand). Finally, AM fungi may have a 'priming' effect, through which they stimulate other soil microbes in the rhizosphere involved in nutrient cycling via decomposition of organic matter [79, 80], providing a net benefit to plants, which could cause them to maintain $\mathrm{C}$ allocation to AM fungal symbionts.

The pronounced effect of litter removal on AM fungal community composition also suggests that nutrients from organic sources play an important role in AM fungal nutrition and function. Litter removal differs from all other treatments in that it involves the depletion rather than the addition of nutrients but it affected nearly as many OTUs as $\mathrm{P}$ addition (Fig. 5), even though there was no effect on AM fungal abundance in roots and only a marginal effect in soil (Fig. 1). Interestingly, AM fungal community composition in roots in the litter removal treatment was similar to that in the $\mathrm{N}$-addition treatment (Fig. 5b) suggesting that both treatments exerted similar selective pressures on the AM fungal communities. We speculate that this could be due to an increase in plant demand for $\mathrm{P}$ in both treatments. Although, the litter removal treatment reduced litter and foliar $\mathrm{N}$ concentrations, there was no reduction in the concentration of $\mathrm{P}$ in the litter $[25,30]$, nor a reduction in seedling foliar P (Sheldrake et al., Unpublished Data). This suggests that plants were able to maintain adequate $\mathrm{P}$ supply from alternative organic or inorganic sources in the soil, potentially due to a shift towards P-specialist AM fungal taxa [34].

\section{Conclusions}

We present a large, experimental data set which helps to elucidate the roles of AM fungi in the lowland tropics, and provides a key reference for future studies hoping to link AM fungal community dynamics with symbiotic function, or integrate AM fungi into ecosystem models, notably those incorporating nutrient limitation [10]. We show that $\mathrm{P}$ is the primary nutrient driving plant-AM fungal interactions in this lowland tropical forest, suggesting that AM fungi are a key mechanism by which tropical forests maintain productivity on low-P soils. Interestingly, while both $\mathrm{N}$ - and $\mathrm{P}$-additions elicited reductions in AM fungal abundance, AM fungal communities showed pronounced, yet distinct responses to $\mathrm{N}$ - and P-addition. Our findings suggest that AM fungal interactions with plants are more sensitive to nutrient imbalances than to the bulk addition of nutrients with leaf litter, and suggest that plants depend on AM fungi to acquire nutrients from organic nutrient pools. The finding that soil and root communities differed in their responses to nutrient availability provides evidence that the 'dual niches' of AM fungi are structured to different degrees by abiotic environmental filters and biotic filters imposed by the plant host, a possibility that warrants further testing. Future work should examine the functional significance of the observed shifts in AM fungal community and abundance in terms of both forest nutrition and $\mathrm{C}$ sequestration; the relative importance of AM fungi versus roots in nutrient uptake from different soil pools; and the mechanisms underlying shifts in plant-AM fungal relations in response to nutrient additions and altered nutrient stoichiometry.

Acknowledgements We thank R. Gonzales, O. Hernandez, J. Rodriguez, N. Fossatti, D. Herrera and J. Castillo for their assistance in the field. A. Herre provided intellectual, technical and moral support. I. Henderson provided advice on the sequencing work and $\mathrm{H}$. Wallander supported the lipid analysis. M.S. was funded by a Smithsonian Tropical Research Institute (STRI) predoctoral fellowship, a Cambridge Home and European Scholarship, the Department of Plant Sciences, Cambridge, and a Cambridge Philosophical Society travel grant. E.J.S. was supported by funding from the European Research Council under the European Union's Seventh Framework Programme (FP/20072013), ERC Grant Agreement No. 307888. The Smithsonian Tropical Research Institute served as the base of operations and provided logistical support.

Author contributions M.S., S.M. and B.L.T. designed the study. E.V. J.T. and E.J.S. established the leaf litter manipulation experiment. S.J. 
W. established the nutrient addition experiment. M.S. and D.R. performed the lab and field work. P.A.O. supported the lipid analysis. N. R. conducted the bioinformatic analysis. E.V. contributed to the analysis and interpretation. M.S. conducted the statistical analysis and wrote the manuscript with input from all authors.

\section{Compliance with ethical standards}

Conflict of interest The authors declare that they have no conflict of interest.

\section{References}

1. Smith SE, Read DJ. Mycorrhizal Symbiosis. 3rd edn. New York, NY: Academic Press; 2008.

2. Alexander I, Lee S. Mycorrhizas and ecosystem processes in tropical rain forest: implications for diversity. In: Burslem D, Pinard M, Hartley S, (eds). Biotic Interactions in the Tropics. Cambridge: Biotic Interactions in the Tropics; 2005. p. 165-203.

3. Dixon RK, Solomon AM, Brown S, Houghton RA, Trexier MC, Wisniewski J. Carbon pools and flux of global forest ecosystems. Science. 1994;263:185-90.

4. McGuire KL, Henkel TW, Granzow de la Cerda I, Villa G, Edmund F, Andrew C. Dual mycorrhizal colonization of forest-dominating tropical trees and the mycorrhizal status of non-dominant tree and liana species. Mycorrhiza. 2008; 18:217-22.

5. Averill C, Turner BL, Finzi AC. Mycorrhiza-mediated competition between plants and decomposers drives soil carbon storage. Nature. 2014;505:543-5.

6. Camenzind T, Hättenschwiler S, Treseder K, Lehmann A, Rillig MC. Nutrient limitation of soil microbial processes in tropical forests. Ecol Monogr. 2017;88:1-60.

7. Kaspari M, Garcia MN, Harms KE, Santana M, Wright SJ, Yavitt JB. Multiple nutrients limit litterfall and decomposition in a tropical forest. Ecol Lett. 2008;11:35-43.

8. Wright SJ, Yavitt JB, Wurzburger N, Turner BL, Tanner EVJ, Sayer EJ, et al. Potassium, phosphorus, or nitrogen limit root allocation, tree growth, or litter production in a lowland tropical forest. Ecology. 2011;92:1616-25.

9. Turner BL, Brenes-Arguedas T, Condit R. Pervasive phosphorus limitation of tree species but not communities in tropical forests. Nature. 2018;555:367-370. doi:10.1038/nature25789.

10. Bonan GB, Hartman MD, Parton WJ, Wieder WR. Evaluating litter decomposition in earth system models with long-term litterbag experiments: an example using the Community Land Model version 4 (CLM4). Glob Change Biol. 2012;19:957-74.

11. Townsend AR, Cleveland CC, Houlton BZ, Alden CB, White JW. Multi-element regulation of the tropical forest carbon cycle. Front Ecol Environ. 2011;9:9-17.

12. Alexander I, Selosse M-A. Mycorrhizas in tropical forests: a neglected research imperative. New Phytol. 2009;182:14-16.

13. Mohan JE, Cowden CC, Baas P, Dawadi A, Frankson PT, Helmick K, et al. Mycorrhizal fungi mediation of terrestrial ecosystem responses to global change: mini-review. Fungal Ecol. 2014;10:3-19.

14. Hodge A, Helgason T, Fitter AH. Nutritional ecology of arbuscular mycorrhizal fungi. Fungal Ecol. 2010;3:267-73.

15. Johnson NC, Wilson GWT, Bowker MA, Wilson JA, Miller RM. Resource limitation is a driver of local adaptation in mycorrhizal symbioses. Proc Natl Acad Sci USA. 2010;107:2093-8.

16. Treseder KK, Allen MF. Direct nitrogen and phosphorus limitation of arbuscular mycorrhizal fungi: a model and field test. New Phytol. 2002;155:507-15.
17. Bever JD, Richardson SC, Lawrence BM, Holmes J, Watson M. Preferential allocation to beneficial symbiont with spatial structure maintains mycorrhizal mutualism. Ecol Lett. 2009;12:13-21.

18. Kiers ET, Kiers ET, Duhamel M, Beesetty Y, Mensah JA, Franken $\mathrm{O}$, et al. Reciprocal rewards stabilize cooperation in the mycorrhizal symbiosis. Science. 2011;333:880-2.

19. Zheng C, Ji B, Zhang J, Zhang F, Bever JD. Shading decreases plant carbon preferential allocation towards the most beneficial mycorrhizal mutualist. New Phytol. 2014;205:361-8.

20. Bever JD. Preferential allocation, physio-evolutionary feedbacks, and the stability and environmental patterns of mutualism between plants and their root symbionts. New Phytol. 2015;205:1503-14.

21. Johnson NC, Angelard C, Sanders IR, Kiers ET, Kiers ET. Predicting community and ecosystem outcomes of mycorrhizal responses to global change. Ecol Lett. 2013;16:140-53.

22. Rillig MC. Arbuscular mycorrhizae and terrestrial ecosystem processes. Ecol Lett. 2004;7:740-54.

23. Orwin KH, Kirschbaum MUF, St John MG, Dickie IA. Organic nutrient uptake by mycorrhizal fungi enhances ecosystem carbon storage: a model-based assessment. Ecol Lett. 2011;14:493-502.

24. Cleveland CC. Nutrient additions to a tropical rain forest drive substantial soil carbon dioxide losses to the atmosphere. Proc Natl Acad Sci USA. 2006;103:10316-21.

25. Johnson NC. Resource stoichiometry elucidates the structure and function of arbuscular mycorrhizas across scales. New Phytol. 2010;185:631-47.

26. Sayer EJ, Joseph Wright S, Wright SJ, Tanner EVJ, Yavitt JB, Harms KE, et al. Variable responses of lowland tropical forest nutrient status to fertilization and litter manipulation. Ecosystems. 2012;15:387-400.

27. Attiwill PM, Adams MA. Nutrient cycling in forests. New Phytol. 1993;124:561-82.

28. Sullivan BW, Alvarez-Clare S, Castle SC, Porder S, Reed SC, Schreeg L, et al. Assessing nutrient limitation in complex forested ecosystems: alternatives to large-scale fertilization experiments. Ecology. 2014;95:668-81.

29. Vályi K, Mardhiah U, Rillig MC, Hempel S. Community assembly and coexistence in communities of arbuscular mycorrhizal fungi. ISME J. 2016;10:2341-51.

30. Vitousek PM. Litterfall, nutrient cycling, and nutrient limitation in tropical forests. Ecology. 1984;65:285-98.

31. Condit R, Engelbrecht BMJ, Pino D, Perez R, Turner BL. Species distributions in response to individual soil nutrients and seasonal drought across a community of tropical trees. Proc Natl Acad Sci USA. 2013;110:5064-5068. doi:10.1073/pnas.1218042110.

32. Sayer EJ, Tanner EVJ. Experimental investigation of the importance of litterfall in lowland semi-evergreen tropical forest nutrient cycling. J Ecol. 2010;98:1052-62.

33. Mirabello MJ, Yavitt JB, Garcia M, Harms KE, Turner BL, Wright SJ. Soil phosphorus responses to chronic nutrient fertilisation and seasonal drought in a humid lowland forest, Panama. Soil Res. 2013;51:215-7.

34. Turner BL, Yavitt JB, Harms KE, Garcia MN, Romero TE, Wright SJ. Seasonal changes and treatment effects on soil inorganic nutrients following a decade of fertilizer addition in a lowland tropical forest. Soil Sci Soc Am J. 2013;77:1357.

35. Yavitt JB, Harms KE, Garcia MN, Mirabello M, Wright SJ. Soil fertility and fine root dynamics in response to 4 years of nutrient $(\mathrm{N}, \mathrm{P}, \mathrm{K})$ fertilization in a lowland tropical moist forest, Panama. Austral Ecol. 2011;36:433-45.

36. Sheldrake M, Rosenstock NP, Revillini D, Olsson PA, Mangan $\mathrm{S}$, Sayer EJ, et al. Arbuscular mycorrhizal fungal community composition is altered by long-term litter removal but not litter addition in a lowland tropical forest. New Phytol. 2017a;214:455-67. 
37. Tanner EVJ, Sheldrake M, Turner BL. Changes in soil carbon and nutrients following 6 years of litter removal and addition in a tropical semi-evergreen rain forest. Biogeosciences. 2016;13:6183-6190. doi:10.5194/bg-13-6183-2016.

38. Wurzburger N, Wright SJ. Fine root responses to fertilization reveal multiple nutrient limitation in a lowland tropical forest. Ecology. 2015;96:2137-46.

39. Sheldrake M, Rosenstock NP, Revillini D, Olsson PA, Wright SJ, Turner BL. A phosphorus threshold for mycoheterotrophic plants in tropical forests. Proc R Soc B. 2017b;284:20162093.

40. Olsson PLA. Signature fatty acids provide tools for determination of the distribution and interactions of mycorrhizal fungi in soil. FEMS Microbiol Ecol. 1999;29:303-10.

41. Simon L, Lalonde M, Bruns TD. Specific amplification of $18 \mathrm{~S}$ fungal ribosomal genes from vesicular-arbuscular endomycorrhizal fungi colonizing roots. Appl Environ Microbiol. 1992;58:291-5.

42. Helgason T, Daniell TJ, Husband R, Fitter AH, Young JPW. Ploughing up the wood-wide web? Nature. 1998;394:431-1.

43. Hao X, Jiang R, Chen T. Clustering 16S rRNA for OTU prediction: a method of unsupervised Bayesian clustering. Bioinformatics. 2011;27:611-8.

44. Katoh K, Misawa K, Kuma K-I, Miyata T. MAFFT: a novel method for rapid multiple sequence alignment based on fast Fourier transform. Nucleic Acids Res. 2002;30:3059-66.

45. Edgar RC. MUSCLE: multiple sequence alignment with high accuracy and high throughput. Nucleic Acids Res. 2004;32:1792-7.

46. Altschul SF, Gish W, Miller W, Myers EW, Lipman DJ. Basic local alignment search tool. J Mol Biol. 1990;215:403-10.

47. Krüger M, Krüger C, Walker C, Stockinger H, Schüßler A. Phylogenetic reference data for systematics and phylotaxonomy of arbuscular mycorrhizal fungi from phylum to species level. New Phytologist. 2012;193:970-984. https://doi.org/10.1111/j. 1469-8137.2011.03962.x.

48. Nakagawa S, Cuthill IC. Effect size, confidence interval and statistical significance: a practical guide for biologists. Biol Rev. 2007;82:591-605.

49. Anders S, Huber W. Differential expression analysis for sequence count data. Genome Biol. 2010;11:R106.

50. Hart MM, Aleklett K, Chagnon P-L, Egan C, Ghignone S, Helgason $\mathrm{T}$, et al. Navigating the labyrinth: a guide to sequencebased, community ecology of arbuscular mycorrhizal fungi. New Phytol. 2015;207:235-47.

51. McMurdie PJ, Holmes S. Waste not, want not: why rarefying microbiome data is inadmissible McHardy AC (ed). PLoS Comput Biol. 2014;10:e1003531.

52. Wang Y, Naumann U, Wright ST, Warton DI. mvabund- an Rpackage for model-based analysis of multivariate abundance data. Methods Ecol Evol. 2012;3:471-4.

53. Webb C. Exploring the phylogenetic structure of ecological communities: an example for rain forest trees. Am Nat. 2000;156:145-55.

54. Crawley MJ. The R Book. Chichester, UK: John Wiley \& Sons; 2012.

55. Venables WN, Ripley BD. (2002). Modern Applied Statistics with S. Springer.

56. Bates D, Machler M, Bolker B, Walker S. Fitting linear mixedeffects models using lme4. J Stat Softw. 2015;67:1-48.

57. Bennett AE, Bever JD. Trade-offs between arbuscular mycorrhizal fungal competitive ability and host growth promotion in Plantago lanceolata. Oecologia. 2009;160:807-16.

58. Treseder K. A meta-analysis of mycorrhizal responses to nitrogen, phosphorus, and atmospheric $\mathrm{CO} 2$ in field studies. New Phytol. 2004;164:347-55.

59. Maherali H, Klironomos JN. Influence of Phylogeny on Fungal Community Assembly and Ecosystem Functioning. Science.
2007;316:1746-1748

doi: $10.2307 / 20036541$ ?ref $=$ no-xroute:5c3a3a2bea41c1f6f948bad40916a3c9.

60. Powell JR, Parrent JL, Hart MM, Klironomos JN, Rillig MC, Maherali H. Phylogenetic trait conservatism and the evolution of functional trade-offs in arbuscular mycorrhizal fungi. Proceedings of the Royal Society B: Biological Sciences. 2009;276 (1676):4237-4245. doi:10.1098/rspb.2009.1015.

61. Clark RB. Arbuscular mycorrhizal adaptation, spore germination, root colonization, and host plant growth and mineral acquisition at low pH. Plant Soil. 1997;192:15-22.

62. Daniels BA, Trappe JM. Factors affecting spore germination of the vesicular-arbuscular mycorrhizal fungus, glomus epigaeus. Mycologia. 1980;72:457-71.

63. van Aarle IM, Olsson PA, Soderstrom B. Arbuscular mycorrhizal fungi respond to the substrate $\mathrm{pH}$ of their extraradical mycelium by altered growth and root colonization. New Phytol. 2002;55:173-82.

64. Wang GM, Stribley DP, Tinker PB, Walker C. Effects of $\mathrm{pH}$ on Arbuscular Mycorrhiza. I. Field observations on the long- term liming experiments at Rothamsted and Woburn. New Phytol. 1993;124:465-72.

65. Kohout $\mathrm{P}$, Doubková $\mathrm{P}$, Bahram M, Suda J, Tedersoo L, Voříšková $\mathrm{J}$, et al. Niche partitioning in arbuscular mycorrhizal communities in temperate grasslands: a lesson from adjacent serpentine and nonserpentine habitats. Mol Ecol. 2015;24:1831-43.

66. Sýkorová Z, Ineichen $\mathrm{K}$, Wiemken A, Redecker D. The cultivation bias: different communities of arbuscular mycorrhizal fungi detected in roots from the field, from bait plants transplanted to the field, and from a greenhouse trap experiment. Mycorrhiza. 2007;18:1-14.

67. Dodd JC, Boddington CL, Rodriguez A. Mycelium of arbuscular mycorrhizal fungi (AMF) from different genera: form, function and detection. Plant Soil. 2000;226:131-151.

68. Hart MM, Reader RJ. Taxonomic basis for variation in the colonization strategy of arbuscular mycorrhizal fungi. New Phytol. 2002;153:335-44.

69. Clapp JP, Young JPW, Merryweather JW, Fitter AH. Diversity of fungal symbionts in arbuscular mycorrhizas from a natural community. New Phytol. 1995;130:259-65.

70. Hempel S, Renker C, Buscot F. Differences in the species composition of arbuscular mycorrhizal fungi in spore, root and soil communities in a grassland ecosystem. Environ Microbiol. 2007;9:1930-8.

71. Liu W, Zhang Y, Jiang S, Deng Y, Christie P, Murray PJ, et al. Arbuscular mycorrhizal fungi in soil and roots respond differently to phosphorus inputs in an intensively managed calcareous agricultural soil. Sci Rep. 2016;6:24902-11.

72. Hodge A, Fitter AH. Substantial nitrogen acquisition by arbuscular mycorrhizal fungi from organic material has implications for N cycling. Proc Natl Acad Sci USA. 2010;107:13754-9.

73. Werner GDA, Kiers ET. Partner selection in the mycorrhizal mutualism. New Phytol. 2015;205:1437-42.

74. Sayer EJ, Tanner EVJ, Tanner EVJ, Cheesman AW. Increased litterfall changes fine root distribution in a Moist Tropical Forest. Plant Soil. 2006;281:5-13.

75. Turner BL, Yavitt JB, Harms KE, Garcia MN, Wright SJ. Seasonal changes in soil organic matter after a decade of nutrient addition in a lowland tropical forest. Biogeochemistry. 2015;123:221-235. doi:10.1007/s10533-014-0064-1.

76. Vargas R, Hasselquist NJ, Allen EB, Allen MF. Effects of a hurricane disturbance on aboveground forest structure, arbuscular mycorrhizae and belowground carbon in a restored tropical forest. Ecosystems. 2010;13:118-28.

77. Blanke V, Renker C, Wagner M, Füllner K, Held M, Kuhn AJ, et al. Nitrogen supply affects arbuscular mycorrhizal colonization 
of Artemisia vulgaris in a phosphate-polluted field site. New Phytol. 2005;166:981-92.

78. Azcón R, Ambrosano E, Charest C. Nutrient acquisition in mycorrhizal lettuce plants under different phosphorus and nitrogen concentration. Plant Sci. 2003;165:1137-45.

79. Herman DJ, Firestone MK, Nuccio E, Hodge A. Interactions between an arbuscular mycorrhizal fungus and a soil microbial community mediating litter decomposition. FEMS Microbiol Ecol. 2012;80:236-47.

80. Nuccio EE, Hodge A, Pett-Ridge J, Herman DJ, Weber PK, Firestone MK. An arbuscular mycorrhizal fungus significantly modifies the soil bacterial community and nitrogen cycling during litter decomposition. Environ Microbiol. 2013;15: 1870-81. 